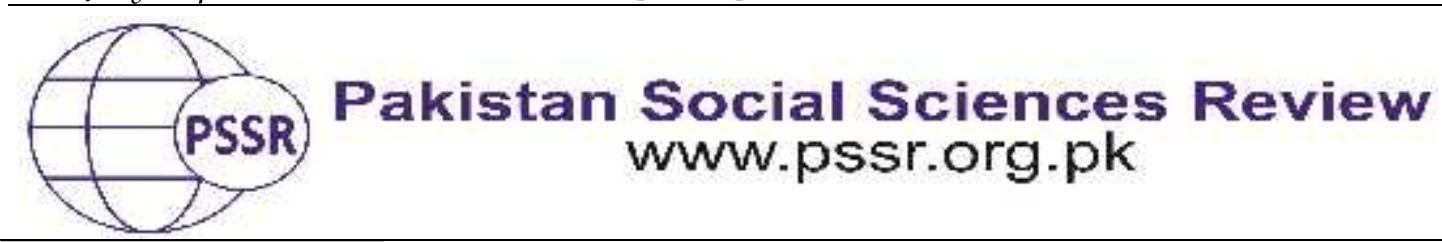

RESEARCH PAPER

\title{
Framing of Pak-Us Relation in US Elite Press
}

\author{
Hafiz Qasir Abbas ${ }^{1}$ Dr. Zahid Yousaf ${ }^{2}$
}

1. PhD. Scholar, Centre for Media and Communication Studies, University of Gujrat, Hafiz Hayat Campus, Gujrat, Punjab, Pakistan

2. Chairperson, Centre for Media and Communication Studies, University of Gujrat, Hafiz Hayat Campus, Gujrat, Pakistan, Punjab, Pakistan

\begin{tabular}{|c|c|}
\hline PAPER INFO & ABSTRACT \\
\hline $\begin{array}{l}\text { Received: } \\
\text { March 17, } 2021 \\
\text { Accepted: } \\
\text { July 01, } 2021 \\
\text { Online: } \\
\text { July 20, } 2021\end{array}$ & $\begin{array}{l}\text { The present study examines the framing of the Pak-US relations } \\
\text { in elite press of the US. The study was focused on the } \\
\text { relationship between Pakistan and the United States of America } \\
\text { in the government of Pakistan's Prime Minister Shahid Khakan } \\
\text { Abbasi. For this, the framing theory was used as the theoretical }\end{array}$ \\
\hline $\begin{array}{l}\text { Keywords: } \\
\text { Elite Press } \\
\text { Framing, } \\
\text { Pakistan, } \\
\text { US, }\end{array}$ & $\begin{array}{l}\text { support for the study and the qualitative content analysis was } \\
\text { selected as the method of the study The New York Times and } \\
\text { The Washington Post selected from the US elite press. There } \\
\text { were two categories on which Pak-US relations were analyzed. } \\
\text { The results revealed that the US press gave unfavorable and }\end{array}$ \\
\hline $\begin{array}{l}\text { *Corresponding } \\
\text { Author }\end{array}$ & $\begin{array}{l}\text { negative coverage to Pak-US relations. It was concluded that the } \\
\text { selected US newspapers had mostly shown unsatisfied behavior } \\
\text { towards the relationship of Pakistan and US. The present study } \\
\text { concluded that the US elite press is giving unfavorable editorial } \\
\text { coverage to Pakistan and damaging the image of Pakistan at the } \\
\text { international level. }\end{array}$ \\
\hline
\end{tabular}

\section{Introduction}

In the present era, mass media has proven its usefulness. The role of media in global communication is very important. Now, individuals are completely reliant on the mass media to obtain information regarding the happening in their neighboring and around the globe (Happer, 2013).Today, media has a major worth at the domestic and global levels. Media give awareness to the general public regarding the latest happenings at the domestic and global levels. Therefore, each media outlet has its specific policy about media coverage and farming the events. This policy creates an impact on the news and this news impact has an impression on international relations at the global level (Ali \& Shahid, 2012).

Ballantyne and Entman and (1993) indicated that media is only the mediator of news and information however it also modifies the rationale of individuals regarding the world happening. It all depends on how media framed the news, information, or events, which aspects of news area highlight and the way it is 
presented creates importance on the minds of viewers regarding the news. Moreover, mass media inform and educate the public with actual details regarding public matters. But media also, instruct the individuals regarding the importance of issues and instruct them that on which issue they should give more importance (Mccombs, 1972).

Jones (2006) explains the importance of the daily newspaper. Daily newspapers surface a notable grind through providing the daily description of events, serving as per administrative extremity, and inspire the autonomy of speech. No other medium, in contrast to daily newspapers is as comprehensive that gives coverage to daily events. Shabbir et al. (2014) stated that the depiction of a country by other country's media can simply calculate the mutual connotation of both countries because this frame comprises beyond the ground position within the world. Correspondingly, Riffle and Yu explain that US media always framed remote countries as pre their country ranks in the world and his interest toward them.

Pak-US relationships have gone through much instability and shared a working relationship. There is a continuous trust discrepancy among both nations. Subsequently 9/11, Pakistan become a part of the US amalgamates and join the hands-on War on Terror that leads Pakistan towards many defies in fighting the extremists inside its region. Throughout this war, media of both nations considerably give coverage to the Pak-US relationship and depicted a particular image of the respective nation for their local viewers (Saqib at el. 2013).

The present study explored how the elite press of the US give editorial coverage to Pak-US relations, during the era of Prime minister Shahid Khaqan Abbasi, who becomes the prime minister of Pakistan after the supreme court of Pakistan disqualified Nawaz Sharif for holding public office, and selected two elite daily newspapers of US (The Washington Post and The New York Times) for this purpose.

\section{Literature Review}

The literature on Pak-US relations is quite developed numerous studies explored US media predominantly throughout the clash, conflict, and army operations and concluded that US media do not demonstrate the complete depiction of reality, however, is always in the favor of US strategies and supervise others (Gitlin \&Hallin, 1993; Zhao\& Hackett, 1994;Lee, 2004; Khan, 2008; Hanan, 2014; Salim, 2007; Safdar., Budiman., \& Nourish, 2014; Salim\& Ryan, 2004; Shabbir,2011; Scheuer, 2009; Siraj,2006). Jamil (2008) conducted a study to examine the portrayal of Pakistan in Us newspapers post 9/11. The results of the study show that US newspapers are framing Pakistan's a very unfavorable image, they are manipulating the fact and positive side of Pakistan and farming Pakistan as a terrorist state which is not the fact. 
Khan (2009) conducted a study on the image of Pakistan in international media and concluded that after 9/11 Pakistan's image in international media is not very good but president Mushraff works a lot to improve and protect the image of Pakistan on an international level. Similarly, Cheem (2016) conducted a study to explore the opinion of foreigners regarding the image of Pakistan which they build after watching the international news coverage on Pakistan, the major question researcher asked is what are the three things that come to your mind when you heard the word Pakistan? Islam, Extremism, nuclear weapons, safety, and Taliban were generally mentioned by the respondents. Therefore, the study concludes that international media is creating the image of Pakistan as a militant state with Islamic extremism.

Shabir and Iqbal (2010) examine the portrayal of Pakistan in American print media and examine the editorial coverage of US newspapers. The results of the study concluded that US media framed Pakistan as a very un-loyal state toward America, and a state of extremist. Similarly, Ali, Jan and Saleem (2013) conducted a study on the image of Pakistan in two American magazines. The researchers examine a total of 128 articles from two magazines, and the results of the study show that both magazines portray a negative image of Pakistan and consider Pakistan as a favorable state for extremists. Correspondingly, Siraj (2008) conducted a study to examine the representation of Pakistan in American daily newspapers. The results of the study show that the coverage of Pakistan related to Pak-India issues is majorly concentrated on peace. The study further concluded that US media and government want that Pakistan and India should resolve their mutual disputes and put their dynamisms to contest against extremism. On the other hand, Brennen and Duffy (2003) conducted a study on the role of media in creating the image of different countries, cultures, and their public. The results of the study show that the role of media is not overlooked in creating the image of different nations, cultures, and their public because media coverage make the mind of its viewers toward the nations, cultures, and their public and treat them according to that image which media has created in their mind.

Correspondingly, McChesney (2002) examines the international coverage of US media. the results of the study show that US media is very bias it always approves the government strategies, and by doing this American media has destroyed the image of many countries. through their one-sided reporting of other nations and manipulation of the facts. The researcher added that the US media safeguards the concern of the dominant class. On the other hand, Zunes and Stephen (2008) examine the escalation of anti-American sentiments in the Middle East and North Africa. The results of the study show that these sentiments were because of the dual standards of US strategies towards these nations and the support of US media on such policies. Correspondingly, Khalid (2001) examines the role of American media in constructing public opinion. The results of the study show that the American public has a strong belief in their media and its plays a vital role in shaping public opinion, therefore how US media depict any nation, event, or issue the general public of America will construct according. 
Likewise, Khan and Irtaza (2010) examine the portal of Pakistan in US media. the results of the study show that American media give very critical and negative to Pakistan, even Pakistan suffer a lot after becoming an ally with the US on the war on terrorism and US media is accepting the effort of Pakistan for this war which effecting Pakistan form inside and outside very critically. Furthermore, Krishnaith (1993) examines the importance of US media. the results show that US media has a strong influence in shaping popular beliefs moreover it also manipulating the decision construction at an administrative level, especially the subjects concerning the external strategies.

The literature shows that US media have a strong influence on public opinion as well as on the policymaking process, therefore how they portray any nation event or society the popular opinion and policies will be generated according. Consequently, it is important to examine how US media is portraying the image of Pakistan in changing political situations in Pakistan. Therefore, the present study explored how the elite press of the US gives editorial coverage to Pak-US relations, during the era of Prime minister Shahid Khaqan Abbasi, who becomes the prime minister of Pakistan after the supreme court of Pakistan disqualified Nawaz Sharif for holding public office.

\section{Theoretical Framework}

The Framing theory gives theoretical support to the present study because this theory gives detailed explanations on the depiction of the subjects through the media. the present study utilized the Framing Theory to analyze the editorial coverage of selected two US dailies. Framing theory points out the substantial features of a subject, it also explores the additional background structures to recognize the version of news amongst the viewers. The framing methods offer diverse opinions on subjects that guide the viewers to determine the proposed connotations of the news or issue (Entman, 2007). Scheufele (2006) considers that media of present age could be categorized by way of 'social constructionist' slant ( $p$. 103) since the viewers accept socially fabricated truth or facts. Correspondingly,the literature concerningmass media framing enfolds numerousissues which specifythe diversity of media framing at native and globaloccasions (Ali, Jan, \& Saleem, 2013; Saleem, 2011 \& Yusof, Hassan, Hassan, \& Osman 2013;).

\section{Material and Methods}

The Present study uses content analysis as the method, content analysis can be defined as a research method in which the substance of any medium of communication is logically documented and investigated (Neuman, 2014). The present study uses qualitative content analysis as a method for data. The universe of the study contains all the editorials of the selected two US dailies, (The New York Times and the Washington Post). All the editorials related to the concern issue during the period of August 2017 to May 2018 are selected as the sample of the study. Unit of analysis in the present study is words, sentences, passages, and even 
the complete editorial, that specify the existence of any of the categories, available in both US dailies. In content analysis, a category is the defined standards and a ratio, which are incorporated over a subject (Sarantakos, 1998: 281). These are the soul for content analysis. it makes the data collection and analysis process very easy and effective. The researchers defined two major categories for the data that are:

A. Pakistan approach towards Pak-US relations

B. US approach towards Pak-US relations

\section{Directions of Contents}

For the dimension of the directions for selected contents of both the US dailies in the present study. The researcher uses the technique of "the totality of the impression" by Berelson (1952). This technique explains the trend of the message, to analysis the trend of the selected content a three-point scale is defined to grade the collected data. That scale is given below.

Positive: The content is measured favorable concerning the study is fall in this scale.

Negative: The content is measure as unfavorable or precarious, and its nature and approach are unfavorable concerning the study is fall in negative scale.

Neutral: The content presents the stability of both unfavorable and favorable opinions regarding this study is fall in neutral scale.

Furthermore, the researcher uses three coders for the study to maintain the inter-coder reliability of the study.

\section{Results and Discussion}

Table 1

Total number of Editorial in both US newspapers during August 2017 to May 2018

\begin{tabular}{ccc}
\hline Newspapers & The New York Times & The Washington Post \\
\hline Numbers of editorials & 56 & 54 \\
Percentage & $51 \%$ & $49 \%$ \\
\hline
\end{tabular}

According to the gathered data total of 56 editorials were published during the selected time duration and the selected issue in The New York Times, similarly, a total of 54 editorials were published in The Washington Post. Therefore, 51\% of the gathered data is from The New York Times and $49 \%$ is from The Washington Post. 
Table 2

Categories of the editorial in both US newspapers

\begin{tabular}{ccc}
\hline Categories & The New York Times & The Washington Post \\
\hline $\begin{array}{c}\text { Pakistan approach towards } \\
\text { Pak-US relations }\end{array}$ & 27 & 27 \\
US approach towards & 27 & 29 \\
Pak-US relations & 54 & 56 \\
Total & $51 \%$ & $49 \%$ \\
Percentage & & \\
\hline
\end{tabular}

Conferring to the gathered data editorial fall in the first category of the data in both newspapers are same number 27, and the editorial fall in the second category are 27 from The New York Times and 29 from The Washington Post, therefore 51\% of the is from The New York Times, from both categories. Furthermore, $49 \%$ of the data is from The Washington Post fall in both categories.

Table 3

The direction of editorial of both US newspapers of category A

\begin{tabular}{ccccc}
\hline & $\begin{array}{c}\text { The New York } \\
\text { Times }\end{array}$ & \multicolumn{3}{c}{$\begin{array}{c}\text { The Washington } \\
\text { Post }\end{array}$} \\
\hline Direction & Frequency & Percentage & Frequency & Percentage \\
\hline Positive & 0 & $0 \%$ & 1 & $4 \%$ \\
Negative & 21 & $78 \%$ & 19 & $70 \%$ \\
Neutral & 6 & $22 \%$ & 7 & $26 \%$ \\
Total & $\mathbf{2 7}$ & $\mathbf{1 0 0} \%$ & $\mathbf{2 7}$ & $\mathbf{1 0 0} \%$ \\
\hline
\end{tabular}

Table no 3 revealed number of directions with a three-pointed scale as positive, negative, and neutral about Pakistan approach towards Pak-US relations from selected two US newspapers. The result showed that the New York times published $0(0 \%)$ positive comments, $21(78 \%)$ observations were negative, and 6 (22\%) neutral observations. The Washington Postpublished1 (4\%) positive annotations, 19 (70\%) negative while 7 (26\%) observations were neutral.

Table 4

The direction of editorial of both US newspapers of category $B$

\begin{tabular}{ccccc}
\hline & $\begin{array}{c}\text { The New York } \\
\text { Times }\end{array}$ & \multicolumn{3}{c}{$\begin{array}{c}\text { The Washington } \\
\text { Post }\end{array}$} \\
\hline Direction & Frequency & Percentage & Frequency & Percentage \\
\hline Positive & 10 & $37 \%$ & 8 & $28 \%$ \\
Negative & 12 & $44 \%$ & 12 & $41 \%$ \\
Neutral & 5 & $19 \%$ & 9 & $31 \%$ \\
Total & $\mathbf{2 7}$ & $\mathbf{1 0 0} \%$ & $\mathbf{2 9}$ & $\mathbf{1 0 0 \%}$ \\
\hline
\end{tabular}

Table no 4 revealed number of directions with a three-pointed scale as positive, negative, and neutral about the US approach towards Pak-US relations 
from selected two US newspapers. The result showed that the New York times published $10(37 \%)$ positive comments, $12(44 \%)$ observations were negative, and 5 (19\%) neutral observations. The Washington Post published8 (28\%) positive annotations, $12(41 \%)$ negative while $9(31 \%)$ observations were neutral

\section{Discussion}

The present study was explored framing the Pak-US relation in the elite newspapers of the United States during the period of Shahid Khakan Abbasi as a prime mister of Pakistan. Who becomes the prime minister of Pakistan after the supreme court of Pakistan disqualified Nawaz Sharif for holding public office. The Washington Post and The New York Times were the US dailies that are selected for the present study. The period was selected for study was from August 2017 to May 2018. The study was depending on two categories and instructions that were utilized in the research process and coding after a comprehensive and cautious investigation from the selected newspapers articles. The classification and headings were chosen and prepared based on the investigation. The study was analyzed on the content order of three points scale as Positive for Favorable, Negative for Unfavorable and Neutral for showing an inclined position.

The first researcher examines how the US elite press gives coverage to PakUS relations. The results of the study show that the selected two dailies were not giving much editorial coverage to the selected issue, which shows the attitude of the US press toward the relationship of Pakistan and US.US elite press give a limited editorial to the selected issue. Then the study further explores the approach of given coverage and divided the data into two categories. The consequences of the study demonstrated that the first classification about Pakistan's attitude towards Pak-US respective relations had a significant difference in both dailies. The New York time did not publish a single editorial on the Pakistani stance toward the US relation in a positive approach they treat Pakistan and Pakistani media very critically and give a very negative and harsh coverage to Pakistani stance. As Shabir and Iqbal (2010) stated that US media framed Pakistan as a very un-loyal state toward America, and a state of extremist. Similarly, Ali and Saleem (2010) concluded that US magazines portray a negative image of Pakistan and consider Pakistan as a favorable state for extremists.

The researcher further examines how the US elite press treated the US approach towards Pak-US relations. On this issue, the approach of US dailies is a bit softer, and they are giving some positive editorial coverage on US stance on Pak-US relations but they are not very much in favor of giving help or support to Pakistan anymore if their government does criticize them. they are not accepting the effort of Pakistan for the improvement of bilateral relations among both countries as Jamil (2008) stated that US newspapers are framing Pakistan's a very unfavorable image, they are manipulating the fact and positive side of Pakistan and farming Pakistan as a terrorist state which is not the fact. 
US elite press is giving unfavorable editorial coverage to Pakistan is damaging the image of Pakistan at the international level. McChesney (2002) concluded that US media is very bias it always approves the government strategies, and by doing this American media has destroyed the image of many countries. through their one-sided reporting of other nations and manipulation of the facts. The researcher added that the US media safeguards the concern of the dominant class. Correspondingly, Khalid (2001) examines the role of American media in constructing public opinion. The results of the study show that the American public has a strong belief in their media and its plays a vital role in shaping public opinion, therefore how US media depict any nation, event, or issue the general public of America will construct according. US media has a strong influence on its public and policymaking therefore US media should give responsible and unbiased coverage on every issue.

\section{Conclusion}

The present study concluded that the US newspaper has given a very negative editorial coverage to Pakistan and Pak-US relations. The coverage of The New York Times is disappointed because they give an unfavorable coverage to Pakistan. non to their editorial is fall in the positive approach, which is very unfortunate. The other selected newspaper the Washington Post is a bit better than the New York post but its overall coverage is also unfavorable toward Pakistan. the present study concluded that the US elite press is giving unfavorable editorial coverage to Pakistan that is damaging the image of Pakistan at the international level. US media has a strong influence in shaping popular beliefs moreover it also manipulating the decision construction at an administrative level, especially the subjects concerning the external strategies, and safeguards the concern of the dominant class. So they are make making a negative public opinion regarding Pakistan through there negative coverage. 


\section{References}

Ali, E., \& Shahid, K. (2012). Media \& Foreign Policy: A Study of Pak-US Relations in US and Pakistani Press, post 9/11 Era (2001-2011). Lap Lambert Academic Publishing.

Ali, Z., Jan, M., \& Saleem, N. (2013). Portrayal of Pakistan by US leading news magazines. Science International, 25, 4.

Berelson, B. (1952). Content analysis in communication research. Free Press.

Cheema, N. (2016). Pakistan's Global Image: Perception and Causes. Asian Affairs Journal Weblog.

Entman, R. M. (2007). Framing bias: Media in the distribution of power. Journal of communication, 57(1), 163-173

Entman, M. L., \& Ballantyne, C. M. (1993). Inflammation in acute coronary syndromes. Circulation, 88(2), 800-803

Happer, C., \& Philo, G. (2013). The role of the media in the construction of public belief and social change. Journal of social and political psychology, 1(1), 321-336.

Hallin, D. C., \& Gitlin, T. (1993). Agon and ritual: The Gulf War as popular culture and as television drama. Political Communication, 10(4), 411-424.

Hackett, R. A., \& Zhao, Y. (1994). Challenging a master narrative: Peace protest and opinion/editorial discourse in the US press during the Gulf War. Discourse $\mathcal{E}$ Society, 5(4), 509-541.

Jones, J. P. (2006). A cultural approach to the study of mediated citizenship. Social Semiotics, 16(2), 365-383.

Khalid M (2001) The US media and the image of Muslim world. Pakistan Perspective 6: 124

Khan MA, Irtaza M (2010) Post 9/11 scenario and image of Pakistan as portrayed by top US newspapers. Journal of Media Studies 25: 1.

Khan, M. A. (2009). India's sikh militants forming ties with Lashkar-e-Taiba and Pakistani intelligence. Terrorism Monitor, 7(1), 1-4.

Khan, H. (2013). Pakistan's Contribution to global war on terror after 9/11. IPRI Journal, 13(1), 37-56.

Krishnaiah J (1993) The evil empire revisited: New York Times coverage of the Soviet intervention and withdrawl from Afghanistan. Journalism Quartrly 70: 648. 
Lee, C.-H. (2004). News Coverage of U.S. War With Iraq: A Comparison of The New York Times, The Arab News, and The Middle East Times, Unpublished PhD thesis. The University of Texas at Austin

McChesney, R. W. (2002). The US news media and World War III. Journalism, 3(1), 14-21.

McCombs, M. E. (1972). Mass media in the marketplace. Journalism and Communication Monographs, 24.

Neuman, W. L., \& Robson, K. (2014). Basics of social research. Toronto: Pearson Canada.

shabbir, G., Hassan, A., Madni, A. R., \& Ahmed, N. (2014). War on Terror: Interplay between Press (Daily the Nation \& Daily Times of India) and Governments (Pakistan \& India) Policies. Global Media Journal: Pakistan Edition, 7(1).

Salim, N. (2007). U.S. Image in Pakistani English dailies Dawn, The Nation and The News with special reference to Pakistan-United States relationship during post cold war era (Unpublished Doctoral Dissertation). Institute of Communication Studies, University of Punjab. Lahore.

Salim, N. \& Hanan, M. A. (2014). Media and conflict resolution: Towards building a relationship model. Journal of Political Studies, 21(1), 179-198

Safdar, A., Budiman, M. A. \& Hamid, A. B. N. (2014). Media conformity of foreign policy: of war on terror by the British press. J.R.S. P, 51(01).

Shabir, Ghulam; Ali, Shahzad; Iqbal, Zafar (2011). US Mass Media and Image of Afghanistan: Portrayal of Afghanistan by Newsweek and Time. South Asian Studies. 26 (1): 83-101

Siraj, S. A. (2006). Image of Pakistan in the US Media: Exploring News Framing. Mass Communication, University of Southern Illinois Carbondale, USA. Post Doctorate Dissertation.

Scheuer, M. (2009). Marching towards hell America and Islam after Iraq. New York, NY: Free Press

Shabir, G., \& Iqbal, Z. (2010). Media Construction of Pakistan's Image: Discourse Analysis of Editorials of the Elite UK Newspapers. China Media Research, 6(3).

Siraj, S. A. (2008). War or peace journalism in elite U.S. newspapers: Exploring news framing in Pakistan- India conflict. Strategic Studies, 28(1). Islamabad, Pakistan: Institute of Strategic Studies

Stephen,M. (2008). Anti-Americanism and US imperialism in Salman Rushdie's Fury. 
Scheufele, B. (2006). Frames, schemata, and news reporting. DOI:10.1515/COMMUN.2006.005

Sarantakos, S. (1998). Varieties of social research. In Social research (pp. 31-71). Palgrave, London.

Saqib, N., Masnoon, M., \& Rafique, N. (2013). Impact of foreign direct investment on economic growth of Pakistan. Advances in Management \& Applied Economics, 3(1), $35-45$. 